\title{
Ranking of Drivers and Barriers for the Green Management Implementation at MSME in Banda Aceh City, Indonesia
}

\author{
Asmawati Hasan ${ }^{1}$ Murni $^{2}$ Junita $^{3}$ Intan Rahmi ${ }^{4}$ \\ ${ }^{1,3,4}$ Magister Management, Economic Faculty Universitas Abulyatama, 23373, Indonesia \\ ${ }^{2}$ Mathematics Education, Faculty of Teacher Training and Education, Universitas Abulyatama, Indonesia \\ ${ }^{*}$ Corresponding author. Email: =
}

\begin{abstract}
The Micro, Small and Medium Enterprises (MSMEs) still have low involvement in being environmentally friendly. Production processes that are associated with environmental pollution, such as the use of hazardous materials, and produce waste that are not properly managed, threaten sustainability. This study aims to determine the driving and inhibiting factors of the green management implementation in the micro, small and medium industries in the city of Banda Aceh. The data used in this study were obtained from perception of 60 MSME doer which randomly selected from 208 MSMEs, according to Office of Cooperative, MSME and Trade of Banda Aceh, in 9 sub districts of Banda Aceh represent the perception of entrepreneurs. Perception of 10 employees of Office Environmental Service, Cleanliness and Beauty of Banda Aceh and also perception of 10 academics or environmental activist representing perception of government and experts. Fuzzy TOPSIS method is used to rank the driver and inhibitor factors. The study found that the five highest driver factors for green management application which are: regulation and law enforcement, employees' awareness and motivation, ability to increase competitiveness, customer demand for environmentally friendly products, knowledge about technology and environment-friendly innovations that can be adopted. Meanwhile, the inhibiting factors are in the aspect of human resources such as low environmental knowledge of employees, lack of training for empowerment, and low ability to adopt technology. Inhibitors from the economic and organizational side are limited financial capacity and the absence of green planning.
\end{abstract}

Keywords: Green Management, Driver Factors Rating, Inhibitor Factors Rating, MSMEs Manufacturer, Fuzzy TOPSIS.

\section{INTRODUCTION}

The Micro, Small and Medium Enterprises Industry has undeniably made an important contribution in increasing people's income and providing employment. On the other hand, the activities of this industry cannot be ignored and can cause environmental pollution in the production process [1], resulting in decreasing environmental quality and incurring social costs. The manufacturing industry also consumes a lot of energy and emits large amounts of greenhouse gases which increase environmental problems such as climate change, pollutants and toxic materials that increase environmental degradation [2]. In fact, this unfavorable effect has not become a serious concern by MSME actors, and the government. The waste produced by these industries, creates odors and pollutes the water, such as in the tofu and tempeh industries, without getting proper treatment. The use of hazardous materials also occurs in small home industries, even in the food industry, such as the use of non-food grade coloring agents, non-food grade preservatives, which directly endanger health. Meanwhile, big industries today continue to receive attention related to environmental risks and are asked to take bigger responsibilities. However, small and medium businesses cannot be excluded, even if their ability to cope with environmental problems is limited [3] ignoring the environmental impact of MSMEs is no longer viable [4]. Most of Small and Medium Enterprises (SMEs) had low level involvement towards sustainability [5].

Green Management (GM) is an alternative for the manufacturing industry towards sustainability. GM can be a variety of techniques that have an impact on reducing waste and environmental pollution [2], this is a holistic company approach taking into account the entire 
business including human resource management and supply chain management. This effort can encourage MSME manufacturing to be more efficient [6], profitable and sustainable [7]. The application of green management in micro, small and medium industries will be different from large industries [8].

For various reasons, MSMEs might have been left out of the social and regulation. The time has arrived in which ignoring the environmental impact of MSME is no longer viable [4]. In developing countries, more than 90 percent of all enterprises outside the agricultural sector are SMEs and micro-enterprises, generating a large proportion of GDP [9]. However, MSMEs face obstacles based on the concentration of management functions, lack of professionalism, and inadequate exposure to the intricacies of GM practice [8]. MSMEs also have many shortcomings including small size, short capital, and dependence on government support [10]. This confirms that MSMEs need assistance in the form of approaches and frameworks to improve their environmental performance. The application of GM to MSMEs needs to be seen from taking a strategic and enlightened perspective, not only to comply with regulations, but also to achieve better financial benefits [8],[11].

This study aims to determine the top five rankings of driven and inhabit factors to the implementation of GM in MSMEs. This is not fully explored in previous studies especially, the preferences of Industrial MSMEs in the Banda Aceh communities that have different knowledge, characteristic and culture from other communities. How the government, environmental experts or activists and MSME actors have preference variations regarding the main drivers and obstacles for the adoption of GM on MSMEs in the city of Banda Aceh? This understanding is very important, to bring MSMEs to be environmentally friendly and sustainable and to avoid misguides government decisions.

\section{METHOD}

\subsection{Classification of Driving Factors and Obstacles to Application of GM}

The initial step in this study is to identify the drivers and obstacles in implementing green management, which have been published in several literatures. The driven factors to be environmentally friendly comes from internal and external aspect of the company. External factors coming from government, community, customers and supply chain partners that can influence various environmental management techniques in an organization. Internal factors such as resource management also affect the readiness of manufacturing MSMEs for GM implementation. Some of the drivers identified from various literature can be seen in Table 1 .

Some of the obstacles identified in the literature regarding barriers to the application of GM in MSMEs can be classified into 3 categories; economic, knowledge and organization. Some of the inhibitors identified from various literature can be seen in Table 2 .

Table 1. Classification of driven factors of green management implementation

\begin{tabular}{|l|c|}
\hline \multicolumn{1}{|c|}{ Driving Factors } & \multicolumn{1}{|c|}{ References } \\
\hline Policies Factors & {$[8],[12],[13],[11],[14]$} \\
\hline Environmental law enforcement / regulation & {$[8],[13],[15]$} \\
\hline Incentive; (such as tax deductions, subsidies) & {$[13],[16]$} \\
\hline Public and market demands & {$[13],[17]$} \\
\hline Local community pressure & {$[18],[19],[16],[14]$} \\
\hline Demands of trade and business associations & {$[20],[21],[22],[23],[7]$} \\
\hline Customer request: customer satisfaction, customer centered. & \\
\hline $\begin{array}{l}\text { Cost savings and increased competitiveness; (efficient use of resources, updating of } \\
\text { products, reducing waste ) }\end{array}$ & {$[24],[25],[26],[17]$} \\
\hline $\begin{array}{l}\text { Supply chain demands (the process of providing environmentally friendly raw materials, timely } \\
\text { and green distribution, efficiency in the production process) }\end{array}$ & {$[27],[28],[29]$} \\
\hline Organizational Internal Encouragement & {$[15],[30],[31]$} \\
\hline Top management commitment & {$[32],[27],[24],[33],[34]$} \\
\hline $\begin{array}{l}\text { Mastery of knowledge and technology (innovation in waste management and reuse, green } \\
\text { innovation in production techniques) }\end{array}$ & \\
\hline Environmental awareness / motivation of employees & \\
\hline
\end{tabular}


Table 2. Obstacles of green management implementation

\begin{tabular}{|l|c|}
\hline \multicolumn{1}{|c|}{ Obstacles } & \multicolumn{1}{|c|}{ References } \\
\hline Economy difficulties & {$[35],[21],[36]$} \\
\hline $\begin{array}{l}\text { High capital / investment costs (initial investment to be environmentally friendly, such as } \\
\text { replacing production machinery / equipment) }\end{array}$ & {$[19],[21],[36],[15]$} \\
\hline \begin{tabular}{l} 
Financial difficulties; MSMEs face a budget dilemma \\
\multicolumn{1}{|c|}{}
\end{tabular} \\
\hline $\begin{array}{l}\text { Adverse profits (such as the perception of profit will be reduced due to using } \\
\text { environmentally friendly inputs / production processes) }\end{array}$ & {$[35],[21]$} \\
\hline Limitations in Organization [37],[13],[17] \\
\hline $\begin{array}{l}\text { Lack of leadership and organizational commitment (such as a commitment to ensuring an } \\
\text { environmentally friendly supply chain) }\end{array}$ & {$[36],[35]$} \\
\hline No plan to be environmentally friendly & {$[32],[24]$} \\
\hline Lack of Knowledge & {$[21],[36]$} \\
\hline Low employee knowledge (HR commitment is still lacking) & {$[10],[38],[21]$} \\
\hline Lack of green training to increase employee knowledge & \\
\hline $\begin{array}{l}\text { Lack of technical innovation and production knowledge (using outdated equipment, } \\
\text { materials that are not environmentally friendly) }\end{array}$ & \\
\hline
\end{tabular}

The preference ranking of drivers and inhibitors of GM application is carried out with the help of a multicriteria decision-making tool (MCDM) which is used to compare and evaluate various conflicting criteria [14]. There are various MCDM techniques and in this study a method in a fuzzy environment is used for the order of preference based on similarity to the ideal solution known as Fuzzy TOPSIS.

Data were collected using questioners and interview. The respondents are the owner or employee of MSME which is involved in decision making. The sample are 29\% (60 unit) of MSMEs which randomly and proportionally selected from 208 MSMEs in 9 sub districts of Banda Aceh, according to Office of Cooperative, MSME and Trade of Banda Aceh, 10 environmental experts, academics or activists and the government represented by the Department of Environmental, Cleanliness and City Beauty (DLHK3) Banda Aceh City as many as ten leaders and employees. The data analyzes using fuzzy theory [39] to express decision makers' judgments in linguistic variables and also make models closer to real life situations. The fuzzy version of the similarity preference technique with the ideal solution (TOPSIS) is used to solve the ranking problem between the identified drivers and obstacles, with three decision makers, namely government, environmental experts or activists and MSME actors. The Fuzzy TOPSIS method is used because it is more intuitive, rational and easy to understand, and it does not involve complex pairwise comparisons and the risk of inconsistency [14]. The fuzzy set uses a scale of 1-9 as the linguistic terminology for the criteria and alternatives, as presented in Table 3.
The TOPSIS fuzzy ranking process goes through the following stages: [14],[27].

Table 3. linguistic terminology for criteria and alternatives

\begin{tabular}{lcc}
\hline $\begin{array}{l}\text { Linguistic terms for } \\
\text { criteria }\end{array}$ & $\begin{array}{l}\text { Linguistic terms } \\
\text { for alternatives }\end{array}$ & $\begin{array}{l}\text { Fuzzy } \\
\text { members }\end{array}$ \\
\hline Not important & Very low & $(1,1,3)$ \\
Less important & Low & $(1,3,5)$ \\
Fairly important & Medium & $(3,5,7)$ \\
Important & High & $(5,7,9)$ \\
Very important & Very high & $(7,9,9)$ \\
\hline Source $[27]$ & &
\end{tabular}

Source [27]

\subsubsection{Define an aggregate fuzzy decision matrix for the criteria}

It is assumed that there is a decision maker denoted as $\mathrm{D}=\{\mathrm{D} 1, \mathrm{D} 2, \ldots, \mathrm{Dj}\}$, which must be evaluated against the criteria $\mathrm{C}, \mathrm{Ci}=\{\mathrm{C} 1, \mathrm{C} 2, \ldots, \mathrm{Cn}\}$. The criterion weights are denoted by wi $(i=1,2, \ldots \mathrm{k})$. The performance rating of each decision maker DM $\mathrm{k}(\mathrm{k}=1$, $2, . . \mathrm{K})$ for each alternative $\operatorname{Dj}(\mathrm{j}=1,2, \ldots, \mathrm{m})$ with respect to criterion $\mathrm{Ci}(\mathrm{i}=1,2, \ldots, \mathrm{n})$. The aggregate fuzzy matrix is denoted by $R_{k}=x_{i j k}(i=1,2, \ldots n), \quad(j=1,2, \ldots m)$, This study identifies three criteria and three decision makers, eleven alternative drivers and eight alternative inhibitors. The calculation of the aggregate fuzzy matrix using equation (1):

$\mathrm{R}=(\mathrm{a}, \mathrm{b}, \mathrm{c}) ; \mathrm{k}=1,2,3$ 


$$
\begin{aligned}
& a=\min _{k}\left\{a_{k}\right\} a=\min _{k}\left\{a_{k}\right\} \\
& b=\frac{1}{K} \sum_{k=1}^{K} b_{k} b=\frac{1}{K} \sum_{k=1}^{K} b_{k} \\
& c=\max _{k}\left\{c_{k}\right\} c=\max _{k}\left\{c_{k}\right\}
\end{aligned}
$$

The aggregate fuzzy decision matrix for the criterion weight is denoted by the equation 2 )

$$
W=\left(w_{1}, w_{2,} \ldots w_{n}\right) W=\left(w_{1}, w_{2 a}, \ldots w_{n}\right)
$$

\subsubsection{Determine the fuzzy decision matrix}

A fuzzy decision matrix for alternative D is built using the following relationship (3):

$$
\begin{aligned}
& c_{1} \quad c_{2} \quad \ldots c_{n} c_{1} \quad c_{2} \quad \ldots c_{n} \\
& D=\underset{D_{2}}{D_{1}} \underset{D_{m}}{\vdots}\left[\begin{array}{ccc}
x_{11} & x_{12} & \ldots x_{1 n} \\
x_{21} & x_{22} & \ldots x_{2 n} \\
\vdots & \vdots & \ldots \\
x_{m 1} & x_{m 2} & \vdots x_{m n}
\end{array}\right] \\
& D=\underset{D_{2}}{D_{1}} \underset{D_{m}}{\Xi}\left[\begin{array}{ccc}
x_{11} & x_{12} & \ldots x_{1 n} \\
x_{21} & x_{22} & \ldots x_{2 n} \\
\vdots & \vdots & \ldots \\
x_{m 1} & x_{m 2} & \vdots x_{m n}
\end{array}\right]
\end{aligned}
$$

\subsubsection{Normalize the fuzzy decision matrix}

The raw data is normalized using linear scale transformations to bring various criterion scales to comparable scales. The R-normalized fuzzy decision matrix is calculated by equation (4):

$$
R=\left[r_{i j}\right]_{n x m} R=\left[r_{i j}\right]_{n x m}{ }_{\mathrm{i}=1,2, . ., \mathrm{n} \text { dan } \mathrm{j}=1,2, \ldots,}
$$

$\mathrm{m}$

(4)

In which

$$
r_{i j}=\left(\frac{a_{i j}}{c_{j}}, \frac{b_{i j}}{c_{j}^{*}}, \frac{c_{i j}}{c_{j}^{*}}\right) \text { and } c_{i j}=\max \left(c_{i j}\right)
$$

$r_{i j}=\left(\frac{a_{i j}}{c_{j}^{*}}, \frac{b_{i j}}{c_{j}^{*}}, \frac{c_{i j}}{c_{j}^{*}}\right)$ and $c_{i j}=\max \left(c_{i j}\right)$

criteria are favorable or important.

\subsubsection{Determine the weighted normalization matrix}

The weighted normalization matrix $\mathrm{V}$ for the alternatives is calculated by multiplying the weight $\mathrm{w}_{\mathrm{j}}$ of the aggregate fuzzy matrix for the evaluation criteria by the normalized fuzzy decision matrix as given by equation (5):

$$
\begin{aligned}
& V=\left[v_{i j}\right]_{n x m} \quad V=\left[v_{i j}\right]_{n x m} \\
& i=1,2, \ldots, n \\
& \text { and } \\
& \mathrm{j}=1,2, \ldots, \mathrm{m}
\end{aligned}
$$

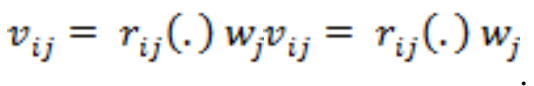

\subsubsection{Determine the positive fuzzy ideal solution (FPIS) and fuzzy negative ideal solution (FNIS)}

FPIS and FNIS in Table 6 and Table 7 are calculated by equations (6) and (7), respectively:

$$
D^{+}=\left(v_{1}^{+}, v_{2}^{+}, \ldots v_{m}^{+}\right) D^{+}=\left(v_{1}^{+}, v_{2}^{+}, \ldots v_{m}^{+}\right)
$$

which

$$
v_{j}^{+}=\max \left(v_{i j}\right) v_{j}^{+}=\max \left(v_{i j}\right)
$$

$\mathrm{i}=1,2, \ldots, \mathrm{n}$ dan $\mathrm{j}=1,2, \ldots, \mathrm{m}$

$$
D^{-}=\left(v_{1}^{-}, v_{2}^{-}, \ldots m\right) D^{-}=\left(v_{1}^{-}, v_{2}^{-}, \ldots m\right)
$$

\[ v_{j}^{-}=\min \left(v_{i j}\right) v_{j}^{-}=\min \left(v_{i j}\right) \]
which $; \mathrm{i}=1,2, \ldots, \mathrm{n}$

\subsubsection{Calculate the distance of each alternative of the FPIS and FNIS}

The distance

$$
\left.\left.v_{i}^{+}, v_{i}^{-}\right) v_{i}^{+}, v_{i}^{-}\right)
$$

from each alternative weight $\mathrm{i}=1,2, \ldots, \mathrm{n}$ of the FPIS and FNIS is calculated using the equation for the distance of two fuzzy triangles. Suppose $\mathrm{D}^{+}=\left(\mathrm{a}_{1}, \mathrm{a}_{2}, \mathrm{a}_{3}\right)$ and $\mathrm{b}=\left(\mathrm{b}_{1}, \mathrm{~b}_{2}\right.$, $b_{3}$ ) is the alternative weighted number, then the distance between them is given by following the relationship in equations (8), (9) and (10) using the conversion method.

$$
\begin{aligned}
& d(a, b)=\sqrt{\frac{1}{3}\left[\left(a_{1}-b_{1}\right)^{2}+\left(a_{2}-b_{2}\right)^{2}+\left(a_{3}-b_{3}\right)^{2}\right]} \\
& d(a, b)=\sqrt{\frac{1}{3}\left[\left(a_{1}-b_{1}\right)^{2}+\left(a_{2}-b_{2}\right)^{2}+\left(a_{3}-b_{3}\right)^{2}\right]} \\
& d_{i}^{+}=\sum_{j=1}^{n} d_{v}\left(d_{i j}, d_{j}^{+}\right) d_{i}^{+}=\sum_{j=1}^{n} d_{v}\left(d_{i j}, d_{j}^{+}\right) \\
& ; \mathrm{j}=1,2, \ldots \mathrm{m} \\
& d_{i}^{-}=\sum_{j=1}^{n} d_{v}\left(d_{i j}, d_{j}^{-}\right) d_{i}^{-}=\sum_{j=1}^{n} d_{v}\left(d_{i j}, d_{j}^{-}\right) \\
& \mathrm{j}=1,2, \ldots \mathrm{m}
\end{aligned}
$$


which

$$
d_{v}(a, b) d_{v}(a, b)
$$
distance between two fuzzy numbers $a$ and $b$.

\subsubsection{Calculate the coefficient of proximity (CCi) of each alternative}

$\mathrm{CC}_{\mathrm{i}}$ represents the distance to FPIS $\left(\mathrm{D}^{+}\right)$and FNIS $\left(\mathrm{D}^{-}\right)$simultaneously. The proximity coefficient of each alternative is calculated using equation (11):

$$
C C_{i}=\frac{d_{i}^{-}}{d_{i}^{-}+d_{i}^{+}} C C_{i}=\frac{d_{i}^{-}}{d_{i}^{-}+d_{i}^{+}} \quad ; i=1,2, \ldots \mathrm{n} .
$$

\section{RESULT AND DISCUSSION}

\begin{tabular}{|c|c|c|c|}
\hline Drivers & Industry & Expert & Government \\
\hline D1. Law and regulatory enforcement & $(1,7.5,9)$ & $(5,8.08,9)$ & $(3,7.8,9)$ \\
\hline D2. Incentives provided by the government & $(1,7.5,9)$ & $(1,6.69,9)$ & $(3,7.8,9)$ \\
\hline D3. Pressure from the local community & $(1,7.3,9)$ & $(3,7.77,9)$ & $(1,6.2,9)$ \\
\hline D4. Pressure from trade associations & $(1,6.8,9)$ & $(3,7,9)$ & $(1,6.2,9)$ \\
\hline D5. Customer demand & $(1,7.6,9)$ & $(3,8.08,9)$ & $(3,7.4,9)$ \\
\hline D6. Save cost & $(1,7.1,9)$ & $(3,7.77,9)$ & $(3,6.8,9)$ \\
\hline D7. Increase competitiveness & $(3,7.7,9)$ & $(3,7.77,9)$ & $(3,7.8,9)$ \\
\hline D8. Supply Chain Pressure & $(1,7.1,9)$ & $(1,6.96,9)$ & $(3,7.4,9)$ \\
\hline D9. Commitment from top management & $(1,7.4,9)$ & $(1,6.69,9)$ & $(1,6.9,9)$ \\
\hline D10. Environmental knowledge and technology & $(1,7.3,9)$ & $(3,8.08,9)$ & $(3,7.4,9)$ \\
\hline D11. Environmental employee awareness and motivation & $(1,7.3,9)$ & $(5,8.08,9)$ & $(3,7,9)$ \\
\hline Criteria $\left(\mathrm{W}_{\mathrm{ij}}\right)$ & $(1,7,9)$ & $(3,5.67,9)$ & $(3,6.33,9)$ \\
\hline
\end{tabular}

Table 4. Fuzzy decision matrix for criteria and alternatives to drive GM implementation

\begin{tabular}{|c|c|c|c|}
\hline Barriers & Industry & Expert & Government \\
\hline B1. High capital costs & $(1,5.4,9)$ & 9) $(1, \quad 5.46$, & $(1,4.8,9)$ \\
\hline B2. Limited financial resources & $(1,6.9,9)$ & $(1,7.15,9)$ & $(3,6.6,9)$ \\
\hline B3. Adverse profit & $(1,3.9,9)$ & 7) $\quad(1, \quad 2.69$, & $(1,3.4,9)$ \\
\hline B4. Lack of leadership commitment & $(1,6,9)$ & $(1,6.89,9)$ & $(1,6,9)$ \\
\hline B5. No green planning & $(1,6.9,9)$ & 9) $(3, \quad 7.31$, & $(1,6.4,9)$ \\
\hline B6. Low environmental knowledge of employees & $(1,7.7,9)$ & $(5,8.08,9)$ & $(3,7,9)$ \\
\hline B7. Low green training and employee empowerment & $(1,7.3,9)$ & 9) $(3, \quad 7.69$, & $(3,6.9,9)$ \\
\hline B8. Low mastery of technology and innovation & $(1,7.3,9)$ & 9) $(1,6.69$, & $(3,7,9)$ \\
\hline Criteria ( $\left.w_{\mathrm{ij}}\right)$ & $(7,9,9)$ & 9) $\quad(1, \quad 5.67$ & $(5,7,9)$ \\
\hline
\end{tabular}

Table 5. Fuzzy decision matrix for criteria and barrier alternatives to GM application aggregates for criteria and alternatives driving the application of GM in terms of policy aspects, community and market demands and internal organizations / MSMEs. Meanwhile, the alternative obstacle is identified from the economic, organizational, and knowledge aspects including technical knowledge. The perspective of decision makers, namely industry/SMEs, government and environmental experts or activists, then compiled a decision matrix using equations 1), 2) and 3), presented in Table 4 and Table 5. Matrix of Normalization result and normalization weighted of the decision matrix and determination FPIS and FNIS, which is calculated using equation 4 ) to the equation 7), are presented in Table 6 and Tabel 7
The results of linguistic assessment and fuzzy 
Table 6. Normalized and weighted normalized decision matrix for alternatives (i.e., drivers)

\begin{tabular}{|c|c|c|c|c|c|c|}
\hline \multicolumn{4}{|c|}{ Normalized } & \multicolumn{3}{|c|}{ Weighted Normalized } \\
\hline Drivers & Industry & Expert & Government & Industry & Expert & Government \\
\hline D1 & $(0.11,0.83,1)$ & $(0.56,0.89,1)$ & $(0.33,0.87,1)$ & $(0.11,5.83,9)$ & $(1.67,5.68,9)$ & $(1.00,5.49,9)$ \\
\hline D2 & $(0.11,0.83,1)$ & $(0.11,0.74,1)$ & $(0.33,0.87,1)$ & $(0.11,5.20,9)$ & $(0.33,4.21)$, & $(1.00,5.49,9)$ \\
\hline D3 & $(0.11,0.81,1)$ & $(0.33,0.86,1)$ & $(0.11,0.69,1)$ & $(0.11,6.04,9)$ & $(1.00,4.9,9)$ & 9) $(0.33,4.36$, \\
\hline D4 & $(0.11,0.76,1)$ & $(0.33,0.78,1)$ & $(0.11,0.69,1)$ & $(0.11,5.44,9)$ & $(1,4.41,9)$ & 9) $(0.33,4.36$, \\
\hline D5 & $(0.11,0.84,1)$ & $(0.33,0.90,1)$ & $(0.22,0.82,1)$ & $(0.11,6.28,9$ & $(1,5.09,9)$ & 9) $(1.00, \quad 5.20$, \\
\hline D6 & $(0.11,0.79,1)$ & $(0.33,0.86,1)$ & $(0.33,0.76,1)$ & $(0.11,6.04,9)$ & $(1,4.90,9)$ & 9) $\quad(1.00, \quad 4.78$, \\
\hline D7 & $(0.33,0.86,1)$ & $(0.33,0.86,1)$ & $(0.33,0.87,1)$ & $(0.33,6.04,9)$ & $(1,4.90,9)$ & $(1.00,5.49,9)$ \\
\hline D8 & $(0.11,0.79,1)$ & $(0.11,0.77,1)$ & $(0.33,0.82,1)$ & $(0.11,5.41,9)$ & $(0.33,4.38,9)$ & 9) $(1.00, \quad 5.20$, \\
\hline D9 & $(0.11,0.82,1)$ & $(0.33,0.85,1)$ & $(0.11,0.77,1)$ & $(0.11,5.98,9)$ & $(1,4.84,9)$ & 9) $(0.33,4.85$, \\
\hline $\begin{array}{ll} & \text { D1 } \\
0 & \end{array}$ & $(0.11,0.81,1)$ & $(0.33,0.90 .1)$ & $(0.33,0.82,1)$ & $(0.11,6.28,9)$ & $(1,5.09,9)$ & 9) $\quad(1.00, \quad 5.20$, \\
\hline 1 D1 & $(0.11,0.81,1)$ & $(0.56,0.90,1)$ & $(0.33,0.78,1)$ & $(0.11,6.28,9)$ & $(1.67,5.09,9)$ & 9) $(1.00, \quad 4.92$, \\
\hline & & & FPIS D+ & $(9,9,9)$ & $(9,9,9)$ & $(9,9,9)$ \\
\hline & & & FNIS D- & $(0.11,0.11,0.11)$ & $(0.33,0.33,0.33)$ & $(0.33,0.33,0.33)$ \\
\hline
\end{tabular}

Table 7. Normalized and weighted normalized decision matrix for alternatives (i.e., Barriers)

\begin{tabular}{|c|c|c|c|c|c|c|}
\hline \multirow[b]{2}{*}{ Barriers } & \multicolumn{3}{|c|}{ Normalized } & \multicolumn{3}{|c|}{ Weighted Normalized } \\
\hline & Industry & Expert & Government & Industry & Expert & Government \\
\hline B1 & $(0.11,0.6,1)$ & $(0.11,0.61,1)$ & $(0.11,0.53,1)$ & $(0.78,5.4,9)$ & $(0.11,3.44,9)$ & $(0.56,3.73,9)$ \\
\hline $\mathrm{B} 2$ & $(0.11,0.77,1)$ & $(0.11,0.79,1)$ & $(0.33,0.73,1)$ & $(0.78,6.9,9)$ & $(0.11,4.5,9)$ & $(1.67,5.13,9)$ \\
\hline B3 & $(0.11,0.43,1)$ & $(0.11,0.30,0.78)$ & $(0.11,0.38,1)$ & $(0.78,3.9,9)$ & $(0.11,1.69,7)$ & $(0.56,2.64,5)$ \\
\hline $\mathrm{B} 4$ & $(0.11,0.67,1)$ & $(0.11,0.77,1)$ & $(0.11,6.7,1)$ & $(0.78,6,9)$ & $(0.11,4.34,9)$ & $(0.56,4.67,9)$ \\
\hline B5 & $(0.11,0.77,1)$ & $(0.33,0.81,1)$ & $(0.11,7.1,1)$ & $(0.78,6.9,9)$ & $(0.33,4.61,9)$ & $(0.56,4.98,9)$ \\
\hline B6 & $(0.11,0.86,1)$ & $(0.56,0.90,1)$ & $(0.33,7.8,1)$ & $(0.78,7.7,9)$ & $(0.56,5.09,9)$ & $(1.67,5.44,9)$ \\
\hline B7 & $(0.11,0.81,1)$ & $(0.33,0.85,1)$ & $(0.33,7.7,1)$ & $(0.78,7.3,9)$ & $(0.33,4.84,9)$ & $(1.67,5.37,9)$ \\
\hline B8 & $(0.11,0.81,1)$ & $(0.11,0.74,1)$ & $(0.33,7.8,1)$ & $(0.78,7.3,9)$ & $(0.11,4.21,9)$ & $(1.67,5.44,9)$ \\
\hline & & & FPIS D ${ }^{+}$ & $(9,9,9)$ & $(9,9,9)$ & $(9,9,9)$ \\
\hline & & & FNIS D- & $(0.78,0.78,0.78)$ & $(0.11,0.11,0.11)$ & $(0.56,0.56,0.56)$ \\
\hline
\end{tabular}

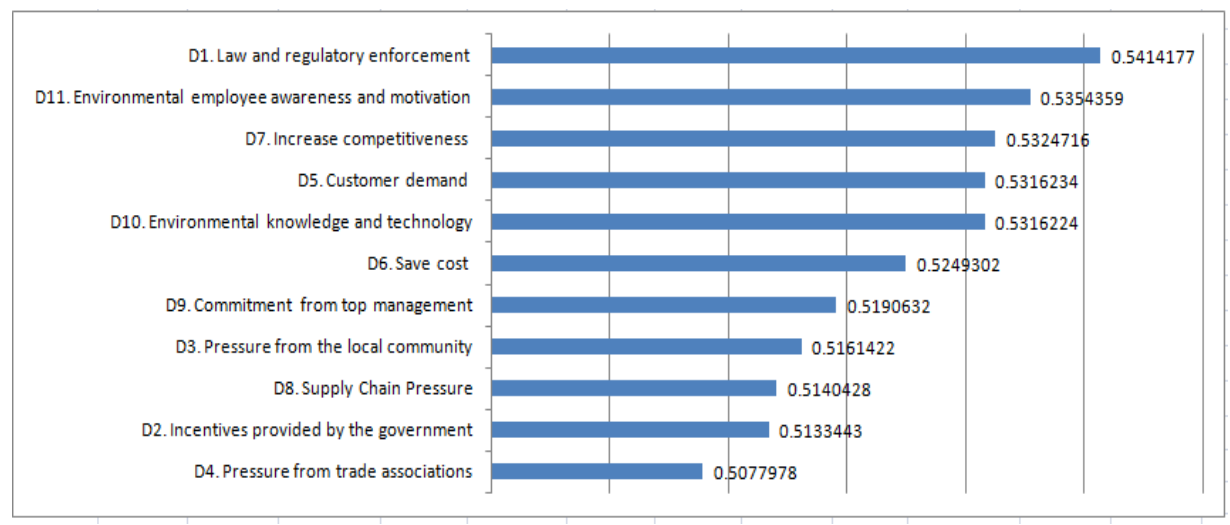

Figure 1 Closeness coefficient and ranking of driver's green management applications at MSMEs 
Figure 1 shows the results of an aggregate ranking showing the five most important drivers for green management applications are law enforcement and rules (driver 1). These findings are [12], which states the law remains the main driver for engaging SMEs in environmental management initiatives. Reports from other studies that put "regulatory pressure" are the main drivers [27],[8],[21]. Today, for various reasons, MSMEs seem to have been left out of regulatory pressures regarding environmental and social impacts.

The awareness and motivation of employees (driving factor 2). Employees who are motivated and have awareness of the importance of maintaining environmental sustainability, is an important driver for MSMEs to implement GM. MSMEs have few employees, so concrete actions of employees who exhibit environmentally friendly behavior are very important. [40] mentions the internalization of values, behaviors, beliefs, and actions necessary for ongoing management practices.

The next important driver is improved competitiveness (driving factor 3). Product competitiveness is an important consideration for implementing GM. This demands that product performance need to be considered [41],[19], competitiveness will be better by using green management [21].

There is general agreement among SMEs that the consumer relationship and the benefits of enjoyment from the product are important aspects to [41],[37]. Customer demand for eco-friendly products includes critical drivers in the application of GM (driver 4), such as the use of eco-friendly packaging, the use of non-toxic materials, not detrimental to health and easily decomposed. This finding is in line with the findings [21] which also the $4^{\text {th }}$ driving factor green management implementation on Malaysian SMEs. In this case, MSMEs can respond to customer pressure by shifting environmental requirements upstream in the supply chain, either by collaborating or by monitoring supplier environmental performance.

The fifth driving factor is technical knowledge and technological innovation mastered by MSMEs. Human resources that master knowledge and technology are important factors for standardizing work, minimizing engine damage, improving efficiency and innovating techniques. Because the core competencies and green innovation performance of SMEs are all significantly less than large companies [10] then need to share knowledge in UMKM and large companies. In this context, [15] argued that food and beverage companies are more prone to innovating in environmentally friendly processes in products.

Other important drivers beyond the five main drivers are cost savings and top management commitments (factors 6 and 7). The implementation of green management means saving energy, water, the use of more efficient production factors, ultimately saving costs. This requires top management initiatives and commitments. Cost savings are a more important driver from an economic perspective. [27] Pressure from the local community (driver 8 ) is the next driving factor. Small and Medium Enterprises (SMEs) still have low levels engagement towards sustainability [5] supply chain pressure, raw material supplier, timely delivery of materials and product distribution and emission reduction are the most critical criteria for greenness [25]. Incentive from the government (driving factor-10) in the form of tax deduction and subsidies are the next driver and less important in encouraging MSMEs for GM applications. Likewise, the pressure from trade and business associations (driving factor 11). This can happen because the marketing reach of MSME products is relatively local.

The closeness coefficient and ranking of inhibitor factors are calculated using equation 8) to equation 11), and the results are presented in Figure 2.

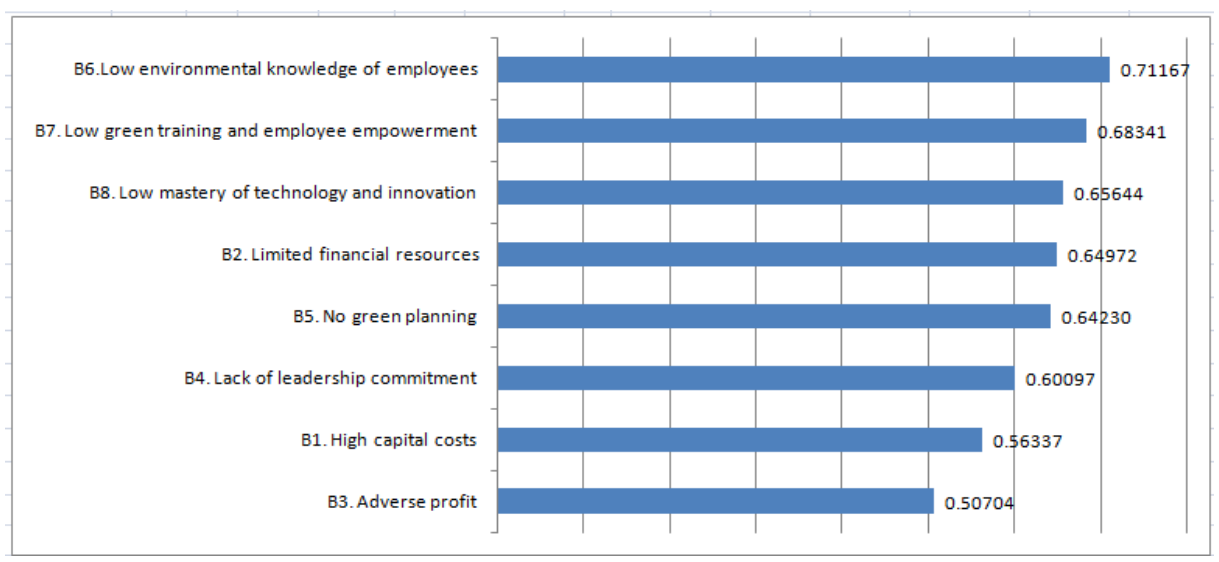

Figure 2 Closeness coefficient and ranking of inhibitors 
Furthermore, the five main inhibitors in MSMEs' GM implementation are the low environmental knowledge of employees (inhibitor 1) limited resources in organizations that have knowledge of environmental sustainability. It is an important inhibitor. This situation is exacerbated by low environmental training for employee empowerment (inhibitor-2), it in line [21]. Empowering employees to support GM implementation is a very important factor considering that employee awareness and motivation are the main driving factor for GM implementation. When employee knows its limitation, the ability to implement GM is also hampered. The next serious obstacle is the lack of technological mastery (inhibitor -3). MSMEs are certainly very limited in development and research for technology development while technological innovation is an important factor for implementing GM. In this conference, large companies or the education world need to collaborate with MSMEs to share their knowledge with green technology innovations. These three main obstacles are related to aspects of human resources.

Limited financial ability to implement GM (inhibitor-4) is a common problem faced by MSMEs. It is also related to the high initial investment or capital costs to start applying GM (inhibitor-7), such as replacing outdated machines, replacing energy-efficient tools, replacing material inputs that do not damage the environment, packaging and others. The obstacle on the organizational side is that there is no green planning (inhibitor -5), which is also related to the low commitment of the leadership (inhibitor -6). MSME employees acting at the peak management level have a prominent influence in the decision-making process and therefore the absence of strong positive commitment from peak management. It is a critical obstacle. As well as the commitment of MSME owners is an important driver for GM implementation. Other obstacles related to the assumption that the implementation of GM will reduce profits (inhibitor -8 ). This perception can also be related to the knowledge and mastery of innovation technology for green technology.

\section{Conclusion}

In the context of Aceh MSMEs. The enforcement of regulations and policies regarding pollution control, emissions reduction and pollution may force MSMEs to start the GM implementation process. This assertiveness is important, because legal products regarding the environment will have no effect without firmness in their implementation. The implication is the government need to further improve law enforcement quickly regarding net transportation and a less destructive production process. Furthermore, improving environmental knowledge and access to green technology innovation and the ins and outs of GM practices in MSMEs which can increase employees' professional awareness, motivation and commitment and top management. This commitment of human resources can drive and eliminate the obstacles that MSMEs face in applying GM including making a good planning. In addition, financial support is still required by MSMEs to apply GM.

Success or failure of obstacle-based management clarification and GM driving factors and solutions in various places, will depend heavily on the inherent characteristics of the solution itself, and the ability to adopt or adapt it under the specific conditions of the operating environment. Adapting to the socio-politics, cultural and economic environment. In fact, businesses must be embedded in clean technology to be sustainable and competitive.

\section{ACKNOWLEDGMENT}

The author is grateful for the opportunity to present this result at the 2nd BIS 2020. We also thank the Director General of Higher Education that provide financial support for this study, LLDIKTI and The Research Institution of Universitas Abulyatama for providing administration support needed in this research.

\section{REFERENCES}

[1] T. M. Choi, C. K. Y. Lo, C. W. Y. Wong, and R. W. $\mathrm{Y}$. Yee, "Green manufacturing and distribution in the fashion and apparel industries," International Journal of Production Economics, 2012.

[2] G. Dilip Maruthi and R. Rashmi, "Green Manufacturing: It's Tools and Techniques that can be implemented in Manufacturing Sectors," in Materials Today: Proceedings, 2015, vol. 2, no. 45, pp. 3350-3355.

[3] S.-H. Chun, H. J. Hwang, and Y.-H. Byun, "Supply Chain Process and Green Business Activities: Application to Small and Medium Enterprises,' Procedia - Soc. Behav. Sci., 2015.

[4] G. Nulkar, "SMEs and Environmental Performance - A Framework for Green Business Strategies,' Procedia - Soc. Behav. Sci., 2014.

[5] M. Firdaus and Z. M. Udin, "Green Human Resource Management (GHRM) Towards SME's: A Conceptual View," 4th Int. Conf. Technol. Oper. Mangement, 2011.

[6] D. I. Rinawati, D. P. Sari, S. N. W.P., F. Muljadi, and S. P. Lestari, "Pengelolaan Produksi Menggunakan Pendekatan Lean and Green Untuk Menuju Industri Batik yang Berkelanjutan (Studi 
Kasus di UKM Batik Puspa Kencana)," J@TI UNDIP J. Tek. Ind., 2016.

[7] O. Fisher, N. Watson, L. Porcu, D. Bacon, M. Rigley, and R. L. Gomes, "Cloud manufacturing as a sustainable process manufacturing route," $J$. Manuf. Syst., 2018.

[8] D. Seth, M. A. A. Rehman, and R. L. Shrivastava, "Green manufacturing drivers and their relationships for small and medium(SME) and large Industries," J. Clean. Prod., 2018.

[9] B. Anand, "Reverse Globalization by Internationalization of SME's: Opportunities and Challenges Ahead," Procedia - Soc. Behav. Sci., 2015.

[10] Y. S. Chen, "The driver of green innovation and green image - Green core competence," J. Bus. Ethics, 2008.

[11] N. T. Pham, Z. Tučková, and C. J. Chiappetta Jabbour, "Greening the hospitality industry: How do green human resource management practices influence organizational citizenship behavior in hotels? A mixed-methods study," Tour. Manag., 2019.

[12] B. Zhang, J. Bi, and B. Liu, "Drivers and barriers to engage enterprises in environmental management initiatives in Suzhou Industrial Park, China," Front. Environ. Sci. Eng. China, 2009.

[13] R. Luken and F. Van Rompaey, "Drivers for and barriers to environmentally sound technology adoption by manufacturing plants in nine developing countries," J. Clean. Prod., 2008.

[14] V. K. Mittal and K. S. Sangwan, "Ranking of drivers for green manufacturing implementation using fuzzy technique for order of preference by similarity to ideal solution method," J. MultiCriteria Decis. Anal., 2015.

[15] M. C. Cuerva, Á. Triguero-Cano, and D. Córcoles, "Drivers of green and non-green innovation: Empirical evidence in Low-Tech SMEs," J. Clean. Prod., 2014.

[16] A. Singh, B. Singh, and A. K. Dhingra, "Practices : Drivers and Barriers of Green Manufacturing Practices A Survey of Indian Industries," Int. J. Eng., 2012.

[17] S. Kara, S. Manmek, and C. Herrmann, "Global manufacturing and the embodied energy of products," CIRP Ann. - Manuf. Technol., 2010.
[18] W. Wikhamn, "Innovation, sustainable HRM and customer satisfaction,” Int. J. Hosp. Manag., 2019.

[19] M. R. Faridi and A. Malik, "Customer engagement technology in SME's in Saudi Arabia: Does it ensue in disturbance or disruption," Int. J. Entrep., 2019.

[20] A. Entezaminia, M. Heidari, and D. Rahmani, "Robust aggregate production planning in a green supply chain under uncertainty considering reverse logistics: a case study," Int. J. Adv. Manuf. Technol., 2017.

[21] R. A. R. Ghazilla, N. Sakundarini, S. H. AbdulRashid, N. S. Ayub, E. U. Olugu, and S. N. Musa, "Drivers and barriers analysis for green manufacturing practices in Malaysian smes: A preliminary findings," in Procedia CIRP, 2015.

[22] Y. C. Chen, C. N. Chu, H. M. Sun, R. S. Chen, L. C. Chen, and C. C. Chen, "Application of green collaboration operation on network industry," Int. J. Precis. Eng. Manuf. - Green Technol., 2015.

[23] A. P. de los Rìos, F. J. Hernández-Fernández, L. J. Lozano, and C. Godìnez, "Biocatalytic reactions in ionic liquid media," in Green Solvents II: Properties and Applications of Ionic Liquids, 2012.

[24] A. A. Zaid, A. A. M. Jaaron, and A. Talib Bon, "The impact of green human resource management and green supply chain management practices on sustainable performance: An empirical study," $J$. Clean. Prod., 2018.

[25] S. Thanki, K. Govindan, and J. Thakkar, "An investigation on lean-green implementation practices in Indian SMEs using analytical hierarchy process (AHP) approach," J. Clean. Prod., 2016.

[26] S. Cosimato and O. Troisi, "Green supply chain management," TQM J., 2015.

[27] N. S. Gandhi, S. J. Thanki, and J. J. Thakkar, "Ranking of drivers for integrated lean-green manufacturing for Indian manufacturing SMEs," $J$. Clean. Prod., 2018.

[28] M. A. N. Agi and R. Nishant, "Understanding influential factors on implementing green supply chain management practices: An interpretive structural modelling analysis," J. Environ. Manage., 2017.

[29] S. Félix, J. Araújo, A. M. Pires, and A. C. Sousa, "Soap production: A green prospective," Waste Manag., 2017.

[30] A. K. Panda, R. K. Singh, and D. K. Mishra, "Thermolysis of waste plastics to liquid fuel. A 
suitable method for plastic waste management and manufacture of value added products-A world prospective," Renewable and Sustainable Energy Reviews. 2010.

[31] F. Vilaplana, E. Strömberg, and S. Karlsson, "Environmental and resource aspects of sustainable biocomposites," in Polymer Degradation and Stability, 2010.

[32] J. Y. Yong, M. Y. Yusliza, T. Ramayah, and O. Fawehinmi, "Nexus between green intellectual capital and green human resource management," $J$. Clean. Prod., 2019.

[33] A. A. Teixeira, C. J. C. Jabbour, A. B. L. De Sousa Jabbour, H. Latan, and J. H. C. De Oliveira, "Green training and green supply chain management: Evidence from Brazilian firms," J. Clean. Prod., 2016.

[34] D. Bangwal and P. Tiwari, "Green HRM - A way to greening the environment," IOSR J. Bus. Manag. I, 2015.

[35] G. C. Oliveira Neto, R. R. Leite, F. Y. Shibao, and W. C. Lucato, "Framework to overcome barriers in the implementation of cleaner production in small and medium-sized enterprises: Multiple case studies in Brazil," J. Clean. Prod., 2017.

[36] S. Yaakub and H. K. Mustafa, "Supply Chain Risk Management for the SME's," Acad. J. Interdiscip. Stud., 2015.

[37] S. Laari, J. Töyli, T. Solakivi, and L. Ojala, "Firm performance and customer-driven green supply chain management," J. Clean. Prod., 2016.

[38] V. K. Mittal and K. S. Sangwan, "Prioritizing barriers to green manufacturing: Environmental, social and economic perspectives," in Procedia CIRP, 2014.

[39] L. A. Zadeh, "Fuzzy logic," in Computational Complexity: Theory, Techniques, and Applications, 2013.

[40] Q. A. Nguyen et al., "Why SMEs Invest in Environmental Measures: Sustainability Evidence," J. Bus. Ethics, 2013.

[41] M. C. Cant, J. Wiid, and C. M. Sephapo, "Key factors influencing pricing strategies for small business enterprises (SMEs): Are they important?," J. Appl. Bus. Res., 2016. 